\title{
Artelogie
}

Recherche sur les arts, le patrimoine et la littérature de l'Amérique latine

$9 \mid 2016$

Horizons et perspectives de la culture en Colombie (1990-2015)

\section{Notas sobre la danza contemporánea en Colombia}

\author{
Iván Jiménez
}

\section{OpenEdition}

\section{Journals}

Edición electrónica

URL: http://journals.openedition.org/artelogie/782

DOI: 10.4000/artelogie.782

ISSN: 2115-6395

Editor

Association ESCAL

Referencia electrónica

Iván Jiménez, « Notas sobre la danza contemporánea en Colombia », Artelogie [En línea], 9 | 2016,

Publicado el 20 junio 2016, consultado el 17 noviembre 2020. URL : http://journals.openedition.org/ artelogie/782 ; DOI : https://doi.org/10.4000/artelogie.782

Este documento fue generado automáticamente el 17 noviembre 2020

Association ESCAL 


\title{
Notas sobre la danza contemporánea en Colombia
}

\author{
Iván Jiménez
}

\section{REFERENCIA}

Rodrigo Estrada (coord.), Cuerpo entre líneas, Bogotá, Alcaldía Mayor de Bogotá/Orquesta Filarmónica de Bogotá, 2010, 292p.

Vergara M. C. et al., "Danza contemporánea. Cuerpo y Universidad”, in La Tadeo, 77. Bogotá, Universidad Jorge Tadeo, 2012. Lozano, Plataforma Universitaria de Danza Centro de Arte y Cultura, s.p.

Orozco N. (dir.), Programa de mano. Coreografías colombianas que hicieron historia, Bogotá, Alambique, IDARTES, Ministerio de Cultura, 2012, 218p.

Atuesta J., Carvajal B., Lagos A., Roa M., Huellas y Tejidos. Historias de la Danza Contemporánea en Colombia, Bogotá, Ministerio de Cultura, 2014, 324p.

1 El presente artículo es un intento de organizar algunas "notas sueltas" que hemos venido tomando a lo largo de nuestras investigaciones sobre la danza contemporánea en Colombia ${ }^{1}$. Aunque estos apuntes cobren el aspecto de un gran repertorio - de nombres de artistas y formadores, de títulos de obras, de experiencias y enfoques, de documentos y objetos de estudio -, nuestro propósito no es la exhaustividad, sino ofrecer una mirada de conjunto, que dé cuenta de la vitalidad de los estudios sobre la danza en el país. Por lo tanto, las posibles omisiones, que esperamos poder compensar en trabajos posteriores, no obedecen a los efectos del olvido, sino a los límites de nuestro conocimiento de las fuentes. Asumiendo el riesgo de incurrir en énfasis cuestionables, proponemos una lectura transversal de cuatro textos panorámicos: Cuerpo entre líneas (2010), Danza contemporánea. Cuerpo y Universidad (2012), Programa de mano. Coreografías colombianas que hicieron historia (2012) y Huellas y Tejidos. Historias de la danza contemporánea en Colombia (2014). En nuestra aproximación a estos textos, y a otros estudios más o menos recientes, quisiéramos mostrar los caminos a través de los cuales se ha intentado asir la diversidad de prácticas gestuales y de formas 
coreográficas que han surgido en la Colombia contemporánea ; también consideramos los relatos históricos y las reflexiones en torno al cuerpo que tales prácticas han generado en la última década.

En Colombia, la danza contemporánea, aquella en la que la elaboración de los gestos no depende del sometimiento de los cuerpos a una norma preestablecida, ha ganado su lugar en los grandes festivales de las capitales - Festival Iberoamericano de Teatro y Danza en la ciudad en Bogotá, Bienal de danza de Cali, Festival de Teatro de Manizales, Al Borde Danza Contemporánea en Medellín -, y en espacios más alternativos como el Festival Universitario de la Jorge Tadeo Lozano, o el Festival Pliegues y Despliegues de las Artes Vivas en Bogotá. En la última década, la constancia de las becas y los premios para la investigación habla del interés de las instituciones oficiales, sobre todo el Ministerio de Cultura y el IDARTES (Instituto Distrital de las Artes), en incluir la danza dentro del patrimonio artístico nacional. Una muestra reciente de este reconocimiento oficial del rico acervo dancístico del país es Danza Colombia: En Escena, serie de televisión transmitida entre el 25 y el 29 de abril del 2016, por Señal Colombia. Para empezar a trazar los puntos de referencia de nuestra mirada panorámica, podríamos partir del siguiente balance realizado por la dramaturga e investigadora Juliana Reyes :

3 «A finales de los años setenta, las posibilidades de formación, promoción y creación en danza eran prácticamente inexistentes. Cuarenta años después, los avances son significativos : hay opciones de formación, agrupaciones jóvenes y otras con un trabajo y trayectoria consolidados, apoyos a la creación y a la circulación de las obras, etc., que nos permiten decir que existe un movimiento dancístico en Colombia, que está fortaleciéndose y reflexionando sobre su propio oficio. » (VERGARA et al., 2012: 35)

4 Esta síntesis podría ser ampliada a la luz de la mirada retrospectiva que la bailarina Lina María Gaviria desarrolla ${ }^{2}$, a partir de su trayectoria profesional y de su experiencia como Gerente de Danza del IDARTES. Desde su punto de vista, en medio de una interacción permanente con las danzas folclóricas y con otras manifestaciones de alcance global, como el tango, el flamenco y el hip hop, la danza contemporánea en Colombia ha ido encontrando gestos que dan visibilidad a «las críticas sociales, a la pluralidad de individualidades», y a temas políticos o existenciales como «la problematización del género, el exilio, lo baldío y la muerte». De acuerdo con su periodización, Carlos Jaramillo y la compañía Triknia Khábelioz, Mónica Gontovnik y el grupo Kore Danza Teatro, María Teresa Hincapié y Álvaro Restrepo, aparecen entre las figuras pioneras de los años 80. En la década siguiente, los años 90, destaca la consolidación de la trayectoria de otro grupo de artistas: Peter Palacio, Bellaluz Gutiérrez y Danza Común, Humberto Canessa, Tino Fernández y L'Explôse, Carlos Latorre y Elizabeth Ladrón de Guevara (Om-Tri), Rafael Palacios y Sankofa Danza Afro. Los años 2000 verían la "entrada en escena" de Eduardo Ruiz y Vivian Nuñez (Estrantes), de Natalia Orozco (Tercero Excluido), de Vladimir Rodríguez (Cortocinesis) y María Fernanda Garzón, entre muchos otros.

5 La formación y el recorrido profesional de cada uno de estos artistas, nos remiten a circuitos de transmisión en los que las tradiciones del baile de Colombia entran en interacción con otras tradiciones y prácticas occidentales : el ballet clásico, la llamada danza moderna - en sus vertientes alemana, estadonunidense y francesa -, la postmodern dance newyorkina, la danza contacto, la improvisación, etc. Con respecto a la formación en la ASAB (Academia Superior de Artes de Bogotá) a finales de los 90, el bailarín e historiador Raúl Parra (2005 : 39) había señalado la vigencia del modelo del 
cuerpo filiforme de la danza clásica, y de la figura del bailarín como un «buen técnico "; su reflexión crítica señalaba también la falta de reconocimiento hacia un " cuerpo cultural colombiano ", cuyo origen estaría en la mezcla de lo indio, lo negro y lo blanco. Sin lugar a dudas, los espacios escénicos colombianos han abierto un lugar para la pluralidad y el cuestionamiento de las normas estéticas imperantes. No obstante, la dimensión de lo cultural, es decir, los modos de definir o reconocer lo propio, aparece más como un horizonte problemático que como una cuestión resuelta. Es, en todo caso, lo que observa la psicóloga y artista escénica Laisvie Andrea Ochoa a partir de su labor en ConCuerpos, corporación que se dedica a la danza integrada de personas con y sin discapacidad:

En Colombia, a pesar de estar orgullosos de nuestra diversidad natural y cultural, en la experiencia cotidiana seguimos replicando un modelo colonialista de distinción. Además, estamos tan asustados los unos de los otros, por la profunda huella de violencia que nos aplasta, que dedicamos muchos esfuerzos a diferenciarnos, a separarnos, a no "untarnos". La interacción social está marcada todavía por el racismo y la división de clases, de niveles educativos, económicos y culturales ; que han aprendido a pervivir paralelamente pero sin mezclarse. El mestizaje se ha quedado como eslogan, en tanto que hace parte de nosotros, casi únicamente en el ámbito genético, pero sin una influencia sólida en la manera en la que nos relacionamos . (VERGARA et al., $2012:$ 107).

6 En la siguiente sección, veremos cómo esta diversidad cultural ha sido tenida en cuenta para la construcción de una memoria patrimonial, basada en una definición dinámica y compleja del concepto de obra coreográfica.

\section{De las obras}

7 Articulando la labor de divulgación cultural con las cuestiones historiográficas, en Programa de mano (2012), la fundación Alambique, el Ministerio de Cultura y el IDARTES han realizado "una antología de escrituras corporales", con miras a dinamizar la memoria de las obras coreográficas. La publicación reúne entrevistas, testimonios, breves artículos, fotografías y reproducciones de los programas de mano de 32 piezas escogidas a través de un proceso de selección interactivo. El concepto de obra en el cual se basa la investigación no sólo se refiere a la composición y a la interpretación de los gestos, sino que también remite a los vínculos que artistas y espectadores pueden establecer a través de sus recuerdos. Dicho de otro modo, lo que se denomina « obra » comprende también las huellas que las danzas han dejado en las sensibilidades de quienes las crearon, las interpretaron y las vieron bailar. Por consiguiente, los rasgos formales se consideran tan relevantes como la apropiación social de las piezas o los cambios que éstas hayan podido generar en los modos de percibir la danza. Ya sea con documentos relativos a la recepción del público o con análisis críticos, los espectáculos de gran envergadura - La leyenda del dorado (1973-1975) de Sonia Osorio y el Ballet de Colombia, o el musical La mujer del año (1990) de David Estivel y Rob Barron - cohabitan con obras que ponen de realce las experiencias de mujeres - Tiempo de luna creciente (1992) de Mónica Gontovnik y Koré Danza Teatro, o Réquiem de arena (1995) de Marta Ruiz y Adra Danza -, y con solos intimistas como Rebis (1986) de Álvaro Restrepo o Esa vana costumbre del bolero de Peter Palacio (1998). Más allá del eclectisismo que reflejan, los títulos de las distintas secciones constituyen puntos de referencia que facilitan el 
acceso a la antología : «territorios », « dislocaciones », « soledades ", « sincretismos », " empirismos », « esplendores ", « ritualidades » $\mathrm{y}$ « resistencias ».

8 En nuestro acercamiento a este vasto campo coreográfico, quisiéramos destacar dos ejes transversales : la valorización de los bailes regionales y los vínculos de la danza con lo político. Con respecto al primer eje, Programa de mano ofrece una rica documentación sobre el lugar que las danzas tradicionales han tenido en el trabajo artístico y pedagógico de varios bailarines y coreógrafos colombianos : la herencia de los esclavos negros e indígenas en Cabildo en Carnaval (1976) de Delia Zapata Olivella; la revindicación política de las tradiciones populares en el trabajo de Carlos Franco con las comparsas del Carnaval de Barranquilla (1981-1983); el ritmo del merengue campesino y la esgrima con machete en Los macheteros del Quindío (1992) de Fundanza Armenia ; el andar de las mulas de los arrieros y el paisaje de las fincas en Testamento paisa (2005) de la compañía Orkéseos; los ritos de las culturas andinas e indígenas amazónicas en torno al ayahuasca, ritos que están presentes en La toma del yagé (2005), del Grupo Folclórico La Tierra Mocoa; la incorporación de las fiestas chocoanas en honor de San Francisco de Asís, en San Pacho... jbendito ! (2005), pieza de Rafael Palacios y Sankofa Danza Afro.

9 Además de este énfasis en las tradiciones regionales, Programa de mano promueve el recuerdo de las formas en las que el arte coreográfico ha encarado la realidad política colombiana. Desde esta perspectiva, Raúl Parra confiere un lugar central a $E l$ potro azul (1975), de Jacinto Jaramillo ; en esta pieza cuyo argumento remite a la guerra entre liberales y conservadores - la Violencia de los años cincuenta -, el zapatear de la danza del joropo, "que nos recuerda el cabalgar y las diversas faenas de los jinetes en el llano » (PARRA, OROZCO, 2012: 185), se articula con la danza moderna por medio del trabajo de liberación de la parte superior del cuerpo. Casi medio siglo después de esa guerra bipartidista en la que suele situarse el comienzo del conflicto armado actual, vemos que lo real de la violencia sigue siendo un punto de partida para la creación coreográfica en Colombia. Prueba de ello es Plan Vía (2000), una colaboración entre el coreógrafo austríaco Johan Kresnik, el bailarín Gustavo Llano y el dramaturgo Víctor Viviescas, que apunta a un cuestionamiento abierto y radical sobre el Plan Colombia y sobre la injerencia de los Estados Unidos en la erradicación de los cultivos ilícitos. Presente en Programa de mano, este eje de las relaciones de la danza contemporánea con lo político, estructura otros trabajos de investigación como el estudio que la bailarina Martha Dueñas (2012) ha realizado sobre la « estética de la desaparición » en tres piezas de los años 2000 : La mirada del avestruz (2002) de Tino Fernández y L'Explôse, Campo muerto (2007) de Danza Común y Homo Sacer (2008) del Teatro de Occidente. En este mismo marco, ubicamos también nuestros análisis (Jiménez, 2013 y 2015) sobre las formas del gesto de la marcha - desfiles, errancias, procesiones - en INXILIO (2010), la sinfonía coreográfica que El Cuerpo de Indias ha consagrado a la experiencia del desplazamiento forzado. Lo que percibimos a través de este corpus de obras, es que la larga duración de la guerra - más de cinco décadas - ha generado una proliferación de imaginarios mortíferos en torno al "cuerpo ", esa palabra que solemos utilizar para designar « la dimensión material y sensible de nuestra experiencia » (BERNARD, 2001 : 19). 


\section{De los enfoques}

Recuerdo mucho el primer día de ensayo cuando Tino [Fernández] y [Juliana Reyes] nos pidieron que pensáramos en el recuerdo más triste que tuviéramos, el que más nos hubiera impresionado. [...] Cuando llegó mi turno, caminé hasta adelante como los demás, pero cuando iba a empezar a hablar, las palabras no pudieron salir de mi boca. Estaba realmente impresionada por el recuerdo y lo único que salió de mí fue une explosión de movimiento ; fue tan vivo y real, que algo cambió en mi forma de asumir la danza. La pauta que nos habían dado había sido capaz de hacer explotar el cuerpo de esa forma ; y por primera vez sentí que el movimiento podía venir de otro lugar distinto al cuerpo. En ese instante dejé de sentirme una bailarina contemporánea para ser una mujer que vivía todas las cosas de que hablaba la obra. Marvel Benavides, sobre La mirada del avestruz, diálogo con Juliana Reyes (BENAVIDES, ESTRADA, 2010 : 194-195)

Creo que lo que busco es que la alteración haga experimentar directamente el objetivo que nos lleva a bailar. ¿Para qué ? Quizás para que el cuerpo haga uso de sus sentidos para percibirse y percibir qué está pasando y luego poder expresarse. Así, cada bailarín puede ser el detonante de otras motivaciones que, entrelazadas con las de otros bailarines, hacen de la danza un gran cuerpo que se fuga a través de sus sentidos. Más que una coreografía, sería entralazar estados subversivos que continuamente están transformando la idea inicial; buscar continuamente multiplicar las reacciones, las propuestas, las opciones.

Bellaluz Gutiérrez (GUTIÉRREZ, ESTRADA, 2010 : 229-230)

Estos dos testimonios artísticos, el primero sobre las pautas que impulsan la gestación de la obra, y el segundo sobre la permeabilidad de la escritura coreográfica a los aportes perceptivos de los intérpretes, han sido extraídos de Cuerpo entre líneas (2010), un conjunto de diálogos, fotografías y textos ensayísticos, reunidos bajo la coordinación editorial de Rodrigo Estrada, con el fin de abordar la danza y el arte coreográfico desde distintos frentes: la creación y la interpretación, las prácticas pedagógicas, la interdisciplinariedad (videodanza), las cuestiones históricas... Esta misma pluralidad de enfoques volvemos a encontrarla en Danza contemporánea. Cuerpo y Universidad, el número 77 de la revista La Tadeo (2012): a lo largo de sus seis capítulos - «las posibilidades », «los parámetros », « las asimilaciones », «las intermitencias », « los amateurs profesionales» y "nuestras construcciones»-, y gracias a un diálogo fructífero con otras disciplinas - el teatro, las artes visuales, la literatura, la psicología, la pedagogía, la historia, la filosofía y la antropología -, los autores adoptan una postura reflexiva con respecto a su experiencia como coreógrafos, intérpretes o docentes. Algunos - Isabel Cuesta, Coque Salcedo, Zoitsa Noriega, Álvaro Restrepo y Carlos Eduardo Sanabria - entran de manera abierta en la problemática del cuerpo, aludiendo a todo lo este término puede evocar en materia de experiencias sensoriales, de vivencias propias del espacio, o de conflictos entre la vida íntima y el orden social (patrones de conducta, normas de comportamiento). En otros casos, el discurso se organiza en torno a un aspecto específico de las artes escénicas: el vínculo de la dramaturgia con el oficio del intérprete (Álvaro Fuentes y Juliana Reyes), el espacio escénico como problema (Nadia Lartigue), el performance (Mónica Gontovnik), la improvisación como gesto de escucha (Eduardo Oramas y Natalia Orozco), la interdisciplinariedad en las obras colectivas (Jenny Fonseca), la danza contacto y el concepto de autoría en relación con el momento de la representación (Margarita Roa). Otros artículos se centran en las prácticas discursivas, como la pedagogía (Consuelo Giraldo) o el ejercicio de la crítica (Rodrigo Estrada), que también determinan el curso de la creación de las obras y de su recepción por parte del púlbico. En el contexto de 
esta reflexión colectiva acerca de las relaciones entre la danza y la universidad, Raúl Parra pone de relieve la experiencia de los amateurs; su repaso de las dos décadas del Festival Universitario de Danza Contemporánea, nos permite hacer la transición hacia el último punto que hemos escogido para desarrollar esta mirada panorámica, a saber, las investigaciones sobre la historia de la danza en Colombia.

\section{De las historias}

11 En una entrevista para la revista Nouvelles de danse, el improvisador venezolano David Zambrano decía que la incorporación de gestos venidos de otros lugares, es un elemento constitutivo del oficio de los bailarines ${ }^{3}$, a pesar de su arraigo a los saberes gestuales de su lugar de origen. En el mismo sentido, inscribiéndose en la línea de lo que podríamos llamar una historia transcultural de la danza ${ }^{4}$, Raúl Parra (2005) había subrayado el rol motor de las experiencias de viaje en el desarrollo de la danza en Colombia: "[éste] ha estado marcado por la presencia de profesores, bailarines y coreógrafos extranjeros, así como por colombianos que luego de una estadía en el extranjero, volvieron a su país para transmitir lo que habían aprendido ${ }^{5}$ " (PARRA, 2005 : 46-47). En el estado actual de las investigaciones, los nombres y las migraciones que han impulsado el devenir de la danza contemporánea en Colombia aparecen con bastante nitidez: además de los artistas mencionados por Lina María Gaviria, encontramos la experiencia pionera de Jacinto Jaramillo y su encuentro con la danza moderna de Isadora Duncan, por medio de Irma Erich-Grimme; también está la interacción entre danza clásica, jazz y danza moderna en los Ballets Modernos del español Luis Ruffo; la llegada de la rumana Irina Brecher a principios de los 70, y el lugar central de su academia El Estudio en la transmisión de varios saberes (ballet clásico, técnicas modernas de Graham y Limón, Jazz-Luigui, movimiento creativo) ; la formación de Katy Chamorro en la técnica moderna de Katherine Dunham ; más tarde, en los años 90, el arribo de la bailarina, coreógrafa y pedagoga Marie-France Delieuvin co-directora con Álvaro Restrepo del Colegio del Cuerpo -, cuya trayectoria profesional está marcada por el contacto con varias las figuras de la danza moderna de los dos lados del Atlántico (Jerome Andrews, Françoise y Dominique Dupuy, entre otros) ; en Francia, el encuentro de Ricardo Rozo con la técnica de Merce Cunningham y con el trabajo de la vanguardia postmoderna estadounidense, o el de Bellaluz Gutiérrez con la danza contacto...

Entre los aportes de lo que podría ser una historia transcultural de la danza contemporánea en Colombia, cabe mencionar el estudio de María del Pilar Naranjo (2005) sobre « la emergencia de una danza contemporánea en Medellín entre 1984 y 2005 ». Este proceso de «emergencia » es asociado a un imperativo político y estético : la necesidad de mostrar cuerpos que no sean los de la muerte violenta, ni los de la mercantilización de las relaciones interpersonales. En los recuerdos y testimonios de los artistas entrevistados, se hace palpable la fuerza de la violencia política como factor de la migración. Tales relatos autobiográficos hablan de similitudes y contrastes entre prácticas gestuales identificadas bajo rótulos distintos - «danza moderna », « danza contemporánea ", "expresión corporal "-; también revelan algunos matices de la experiencia de formación en el extranjero, como por ejemplo, el hecho de que los artistas colombianos descubrieran que lo que ya hacían « intuitivamente » en Medellín, tenía un nombre propio en el lugar al que acababan de llegar. Doris Arias, Elsa Borrero, 
Wilson Cano, Lindaria Espinoza, Henry Lou Gómez, Beatriz Gutiérrez, Gustavo Llano, Peter Palacio, Darío Parra, Beatriz Vélez, María Sara Villa y Fernando Zapata son los protagonistas de esta otra historia de la danza, elaborada fuera del centro de la capital del país.

Huellas y Tejidos. Historias de la danza en Colombia (2014) es otro trabajo historiográfico de gran envergadura. Bajo la tutoría de Sofía Mejía Arias, de Danza Común, un equipo de investigadores ha entrevistado a varias personalidades del campo coreográfico colombiano : Leonor Agudelo, Ángela Bello, Leyla Castillo, Olga Lucía Cruz, Hernando Eljaiek, Carlos Latorre, Edgard Sandino, Norma Suárez, Saraya Vargas, María Cristina Vergara y muchos otros, a los cuales ya nos hemos referido. Los textos introductorios presentan las bases epistemológicas y metodológicas de la investigación. Con respecto a la contrucción de las fuentes, Andrés Lagos explica que a través de las entrevistas, se buscaba una «[aproximación] a la historia desde la propia voz de cada protagonista, sobre sus procesos de formación, de creación, y la manera como el contexto sociocultural influenció y sigue influenciando su práctica artística » (2014 : 13). Juliana Atuesta explica los interrogantes que el carácter efímero de la danza le plantea a la historiografía ; sus argumentos confieren legitimidad a una historia hecha de memoria y oralidad, a una historia «abierta, subjetiva, móvil» (2014: 23), que subvierta la cronología de la mentalidad progresista, es decir, a una historia que deje escuchar « los relatos de la danza y las voces de la danza [...], que se entretejen como un complejo de historias plurivalentes y suceden en una compilación de tiempos diversos, de percepciones y de preguntas que surgen ante la necesidad de vivenciar el complejo contexto de la danza del cual participamos » (2014: 22). Por su parte, Bibiana Carvajal destaca los debates en torno a la identidad, punto álgido en el contexto de la globalización uniformadora de nuestro tiempo. Uno de los interrogantes tiene que ver con los modos de asumir la diversidad cultural de Colombia : «Pensar en "ese cuerpo que somos" es pensar en los diferentes orígenes y diferentes mestizajes que caracterizan la cultura del país » (2014: 32). Y a este respecto, las posiciones pueden ser divergentes : mientras algunos bailarines y coreógrafos revindican la existencia de un «cuerpo colombiano ", reconocible por distintos niveles de pertenencia - geográfico, histórico, cultural -, otros viven y conciben el cuerpo como un mero lugar de tránsito de herencias sociales - códigos, lenguajes, esquemas perceptivos, técnicas -, es decir, un espacio de contacto con «saberes culturales » que en última instancia conducen a una "pluralidad de realidades y formas de percibir el mundo » (2014:31). A la luz de los estudios consultados, y al cierre de estas "notas sueltas", vemos que la contemporanediad de la danza en Colombia no sólo se elabora por el rescate y la valorización de las herencias del mestizaje, sino también por la interacción de estas herencias con "todo lo que coexiste ${ }^{6}$ " en el tiempo actual, incluidos los saberes culturales venidos de otras partes. La tendencia a definir o identificar lo propio colombiano, cohabita entonces, necesariamente, con la experiencia de la alteridad gestual. 


\section{BIBLIOGRAFÍA}

ATUESTA J., CARVAJAl B., LAgos A., ROA M., Huellas y Tejidos. Historias de la Danza Contemporánea en Colombia, Bogotá, Ministerio de Cultura, 2014.

BERNARD M., De la composition chorégraphique, Pantin, Centre national de la danse, 2001.

CARRIE H., “À Budapest, on ne prépare pas du tout les crêpes de la même façon qu'au Vénézuela.”, in Entretien avec David Zambrano. Danse nomade. Regards d'anthropologues et d'artistes, Nouvelles de danse, 34 et 35, Bruxelles, Contredanse, 1998.

CUESTA I., Afección, intuición y visualización, el cuerpo que compone, Bogotá, IDARTES, 2013.

DUEÑAS M., Cuando el cuerpo desaparece. Estrategias de representación del cuerpo desaparecido, Bogotá, IDARTES, 2012.

ESTRADA R. (dir.), Cuerpo entre líneas, Bogotá, Orquesta Filarmónica de Bogotá, 2010.

DELATTRE-DESTEMBERG E., GLON M. et OLIVESI V., Écrire l'histoire de la danse : des enjeux scientifiques aux enjeux idéologiques. Carnet de recherche de l'Atelier d'histoire culturelle de la danse, Paris, EHESS, 2013. (Disponible en : http://ahcdanse.hypotheses.org/38 (consultado el 10 de mayo del 2016),

JIMÉNEZ I., "Exclusión y figuras de la comunidad en la coreografía de INXILIO", in Desde el Jardín de Freud., 13, Bogotá, Universidad Nacional de Colombia-Escuela de psicoanálisis, 2013, p. 55-70.

JIMÉNEZ I., "L'être ensemble dans INXILIO, danse et politique en Colombie", in Recherches en danse, 4, 2015. (Disponible en : http://danse.revues.org/1198)

NARANJO M., Émergence de la danse contemporaine à Medellín (Colombie) 1984-2005, tesis de master en danza, Universidad París 8, 2005.

OROzCO N. (dir.), Programa de mano. Coreografías colombianas que hicieron historia, Bogotá, Alambique, IDARTES, Ministerio de Cultura, 2012.

PARRA R., "Danse contemporaine en Colombie, un défi au corps", in Funambule, 7, Saint-Denis, Anacrouse-Departamento de danza Universidad París 8, 2005.

POUILLAUdE F., Le désœuvrement chorégraphique, étude sur la notion d'œuvre en danse, Paris, Vrin, 2014.

VERGARA M. C. et al., "Danza contemporánea. Cuerpo y Universidad”, in La Tadeo, 77. Bogotá, Universidad Jorge Tadeo, 2012. Lozano, Plataforma Universitaria de Danza - Centro de Arte y Cultura.

\section{NOTAS}

1. Luego de dos artículos sobre INXILIO, pieza coreográfica del Cuerpo de Indias que encara la problemática del desplazamiento forzado, nuestras investigaciones actuales se centran en la interacción entre ciencia y danza en el marco del Festival Átomos por la Paz (Bogotá, octubre del 2016), en la práctica de las danzas tradicionales de Ofelia Betancourt y Darío Arboleda, y en la obra de la bailarina y coreógrafa barranquillera Mónica Gontovnik.

2. Entrevista realizada en Bogotá, el viernes 25 de septiembre del 2015. Nuestros agradecimientos sinceros a Lina María Gaviria por haber puesto a nuestra disposición algunas de las publicaciones aquí referenciadas. 
3. «Pienso que está bien que, cada vez que hagamos llegar nuestros pensamientos a nuestros brazos y piernas, estos se extiendan, pero que también está bien saber que igualmente podemos doblarlos de múltiples maneras, y que podemos transformarlos de numerosas formas. Como bailarines, debemos ejercer todas estas posibilidades. ». En francés : «je pense que c'est bien que, lorsque nous étendons nos pensées à travers nos bras et jambes, ceux-ci se tendent, mais c'est tout aussi bien de savoir que nous pouvons également les fléchir d'une multitude de façons différentes, et que nous pouvons les transformer de très nombreuses façons. En tant que danseurs, nous devons nous exercer à ces possibilités » (CARRIE, $1998: 146)$.

4. Sobre una historia cultural de la danza, centrada en las circulaciones, las transferencias gestuales y la captación de prácticas y saberes exógenos, remitimos al artículo de Emmanuelle Delattre-Destemberg, Marie Glon y Vannina Olivesi (2013).

5. «[Celui-ci] a été marqué par la présence de professeurs, danseurs et chorégraphes étrangers, ainsi que par des Colombiens qui, après avoir fait un séjour à l'étranger, sont retournés dans leur pays pour transmettre ce qu'ils avaient appris ».

6. Retomamos aquí el concepto de contemporaneidad propuesto por el filósofo de la danza Frédéric Pouillaude (2014 : 357) : "es “contemporáneo", en su sentido más general y sin que ninguna época específica sea designada, todo lo que coexiste, todo lo que pertenece a un mismo tiempo ». En francés : « est “contemporain”, en son sens le plus général et sans qu'aucune époque ne soit par là désignée, tout ce qui coexiste, tout ce qui appartient à un même temps ».

\section{RESÚMENES}

A partir de una lectura transversal de cuatro textos panorámicos - Cuerpo entre líneas (2010), Danza contemporánea. Cuerpo y Universidad (2012), Programa de mano (2012) y Huellas y Tejidos (2014) - quisiéramos mostrar los caminos a través de los cuales se ha intentado asir la diversidad de prácticas gestuales y de formas coreográficas que han surgido en la Colombia contemporánea; también consideramos los relatos históricos y las reflexiones en torno al cuerpo que tales prácticas han generado en la última década.

\section{ÍNDICE}

Palabras claves: danza contemporánea, Colombia, cuerpo, investigación, historia

\section{AUTOR}

\section{IVÁN JIMÉNEZ}

Docente-investigador del Laboratorio IMAGER

Universidad París-Este Créteil 